\title{
Effects of Knowledge Management and Creation Capability on the Performance of SMEs in Kogi State
}

\author{
Yunusa Ademu*, Folashade Olufunke Obaje ${ }^{* *}$, \\ Rotimi Grace Gift Otitolaiye ${ }^{* * *}$
}

\author{
*PhD. Department of Business Administration, Kogi State University, Anyigba, P.M.B. 1008, Nigeria \\ e-mail: yunusaademu01@gmail.com \\ ** M.Sc. Department of Accounting, Kogi State University, Anyigba, P.M.B. 1008, Nigeria \\ *** PhD. Department of Business Administration, Kogi State University, Anyigba, P.M.B. 1008, Nigeria \\ e-mail: modupenafiu@gmail.com
}

DOI: 10.51865/EITC.2021.01.05

\begin{abstract}
This study aimed at determining the effects of knowledge management and creation capability on the performance of SMEs in Kogi State. The research survey design was adopted for this study. For data analysis, descriptive and inferential analytical techniques were used. The analytical techniques employed are survival analysis and multiple regression analysis (stepwise). Findings showed that socialization has a significant effect on the competitive advantage of both Small and Medium Enterprises in Kogi State; externalization has a significant effect on the competitive advantage of Medium Enterprises in Kogi State; the combination of resources can predict the competitive advantage of both Small and Medium Enterprises in Kogi State. Findings further showed that combination, internalization, socialization, and externalization strongly and significantly predict the business growth of SMEs in Kogi State. The study concluded that the ability of SME owners to manage knowledge can translate into a better chance of achieving the enterprise's goals. The study recommended that SME owners should channel their knowledge creation towards socialization and a combination of resources; owners of Medium Enterprises should take advantage of knowledge creation through externalization to facilitate sustainable competitive advantage in Kogi State. Furthermore, SME owners and economic stakeholders should find alternative ways of promoting effective knowledge management and creation in Kogi State.
\end{abstract}

Keywords: knowledge management; knowledge acquisition; knowledge transfer; knowledge infrastructure capability; organizational performance.

JEL Classification: $D 23 ; M 21 ; 012$.

\section{Introduction}

Today, the dynamism in the business environment, both global and local, demands that organizations possess knowledge creation ability. The SMEs in Kogi State is observed not giving attention to intensive knowledge management. This may be one of the reasons attached to the stampede experienced by many SMEs when it comes to growth evaluation. According to 
Nawab, Nazir, Zahid, and Fawad (2015: 43), the "ability to create and distribute knowledge across the entire organization is therefore compelling drivers for knowledge management".

Knowledge management aids innovations in operations and business activities. Ahlstrom (2010) added that SMEs can only utilize opportunities, enhance product differentiation, and achieve competitive advantage through innovations. Innovations are observed as product knowledge management. It is whispered that firm's innovation is allied with the ability to afford and assimilating new knowledge (Duggan, 2012). Knowledge creation is subject to internal and external assessments. The firm can attain new knowledge from both internal and outside sources (Sofka and Grimpe, 2010). Enterprises 'create new knowledge' within their physical boundaries (internal environment) as well as from outside to prevent rigidity, encourage inventive serendipity, and assess their technological competency against that of competitors (Szulanski, 2001; Easterby-Smith \& Lyles, 2011). SME owns can generate knowledge by experience, training employees on the job, interaction with other enterprises within the same industry

The best way SME owners can be assured of a satisfactory competitive position in the business environment is to ensure effective management of knowledge. Effective management of knowledge can begin by taking inventory of knowledgeable organizational citizens to determine knowledge deficit. Handzic and Hasan (2003) expressed that taking inventory of knowledge in the current organizational context, and conducting analysis on 'strengths versus weaknesses' on this inventory in an overt fashion, is seen as the next necessary phase in a successful knowledge management journey. When the inventory of knowledge is taken, there is a tendency that SME owners will be able to ascertain their strengths or weakness in the business environment. Von Krogh, Ichijo, and Nonaka (2015) advised that SME owners need to allot substantial time to strategic thinking through the available collection of knowledge in their enterprises and where it resides.

Knowledge creation is vital for firms that aim desirable pay off in a competitive war. Salojärvi, Furu, and Sveiby (2005) posited that most firms achieved a competitive edge through knowledge creation. The competitive advantage of some small firms in Kogi State remains uncertain because a majority of SMEs operate on the low key, and are yet to grow since the last five years. SMEs in Kogi State have only grown slowly as a result of their commitment to incremental change; being that it requires less knowledge to adjust and it does not affect the business structure. Factually under normal circumstances, a firm should have a competitive advantage in a specific area in the business environment. Such a competitive advantage may be predicated on the knowledge to forestall radical change in a tough competitive business environment. Nawab et al. (2015) added that Knowledge can also be a competitive advantage for the firms. Also, the survival of SMEs in Kogi State may be due to their level of knowledge created. Wang, Su, and Yang (2011) expressed that enterprises now depend more on building and creating knowledge as an indispensable precondition to survive and thrive in their respective hyper-competitive marketplace.

The main objective of the study was to determine the effects of knowledge management and creation capability on the performance of SMEs in Kogi State. The specific objectives of the study were to:

o Investigate the effects of knowledge creation constructs (socialization, externalization, combination, and internalization) on the competitive advantage of SMEs in Kogi State.

o Ascertain the significant effect of knowledge management activities on the business survival of SMEs in Kogi State.

\section{Literature Review}

Several studies have been conducted using varying concepts concerning the achievement of organizational performance. There has been a huge asserted effort on the effect of resources on 
the performance of firms. According to Riera and Iijima (2017: 31), "the knowledge-based view considers knowledge as the most important resource for a firm". Within the phases of KM, the knowledge creation and integration phases were considered the most important assets of the firm from a strategically point of view (Lewin and Massini, 2004). Nonaka and Takeuchi (1995) conducted a study on the knowledge that led to the establishment of the SECI Model (Socialization, Externalization, Combination, \& Internalization). Riera and Iijima (2017: 13) view the "SECI Model as a model of knowledge creation process which can aid the understanding of the dynamic nature of knowledge creation, and to manage such a process effectively".

In today's business environment, knowledge may be regarded as the most vital resource; as it deals with the intellectual property to be tapped for the achievement of distinctive goals. Wang and $\mathrm{Wu}$ (2011) expressed that knowledge has been the critical element that changes the competition model of business from time to time, and it has been recognized as one of the most important success factors to an organization in many key aspects, such as innovation, quality and so on. Knowledge management and creation capability are thus concerned about how an enterprise can generate useful and incomparable knowledge, utilize or deploy it as an inevitable resource for the achievement of the desired end.

This study is guided by the assumption of the knowledge-based theory and the SECI model. The knowledge-based theory explains the significance of 'knowledge management practices' to the performance of SMEs. The theory assumes that 'socially complex, heterogeneous knowledge bases and capabilities' among enterprises can determine sustainable competitive advantage. The theory only suggested a competitive advantage as the main dependent variable. It shows that the rationale behind creating and managing knowledge is to win the competitive war. In this study, it is upheld that other variables can amount to the competitive advantage of an enterprise if they are pursued and achieved. For example, variables such as customer satisfaction, innovation, and human performance can result in a competitive advantage in the long-run. Gonzalez (2010) asserted that shared knowledge can influence the competitiveness of a firm. Huang (2001) also used 'effectiveness, efficiency, productivity, life quality, innovation, and profitability' as viable measures of SMEs' performance. Gholami et al. (2013: 206) and Abusweilem \& Abualoush (2019) noted that "knowledge management practices such as knowledge acquisition, knowledge storage, knowledge creation, knowledge sharing, and knowledge implementation play a critical role in achieving high-level productivity, financial and human resource performance". The finding of Zack et al. (2009) shows that knowledge management significantly and positively influences the financial performance of firms. Also, Kiessling, Richey, Meng, and Dabic (2009) discovered that knowledge management has positive effects on a firm's innovation, product improvement, and employee improvement. Findings from studies (Fugate, Stank, and Mentzer, 2009; Hussain, Xiaoyu, Si and Ahmed, 2011; Chen and Liang, 2011) also proved that knowledge management significantly and positively influence the SMEs' performance.

Nonaka and Takeuchi (1995) are known for their SECI Model (socialization, externalization, combination, and internalization). The SECI Model focuses on knowledge creation and how it can be utilized for the achievement of competitive advantage. The model also emphasized the importance of effective management of organizational knowledge. Nonaka, Kodama, Hirose, and Kohlbacher (2014) expressed that to achieve competitiveness enterprises must constantly absorb existing knowledge, create new knowledge, and pursue practical wisdom. In their study, $\mathrm{Yu}$, Zhang, Lin, and $\mathrm{Wu}$ (2017) found that the knowledge creation process does not have a significant direct effect on sustainable competitive advantage. Bihamta et al. (2012) the profound roles of knowledge creation in terms of socialization, externalization, combination, and internalization as a model on the quality process were examined. The study of Karimi et al. (2014) found that a significant positive relationship exists between socialization and productivity. This may also translate into the area of competitive advantage, customer satisfaction, and innovation since productivity is also a measure of SMEs' performance. The 
expectation is that socialization will have a linear relationship with a competitive advantage, customer satisfaction, and innovation of SMEs in Kogi State. The study of Na and Kang (2018) also found that 'externalization and internalization' significantly predicts 'distinctive competitive advantage'. There is a likely implication of externalization and internalization on competitive advantage, customer satisfaction, and innovation of SMEs in Kogi State. On another hand, the combination of knowledge resources is likely to have predictive power over competitive advantage, customer satisfaction, and innovation of SMEs in Kogi State. Kamya, Ntayi, and Ahiauzu (2010: 2979) expressed that "combination of knowledge management implies acquisition, dissemination, and responsiveness to knowledge and market orientation that has the customer and competitor as the center of attention". The findings of studies (Teece, Pisano and Shuen, 1997; O'Regan and Ghobadian, 2004) revealed that a combination of knowledge management can facilitate the achievement of competitive advantage. Kamya et al. (2010) also found that a combination of knowledge-based resources has a significant effect on the competitive advantage of a firm.

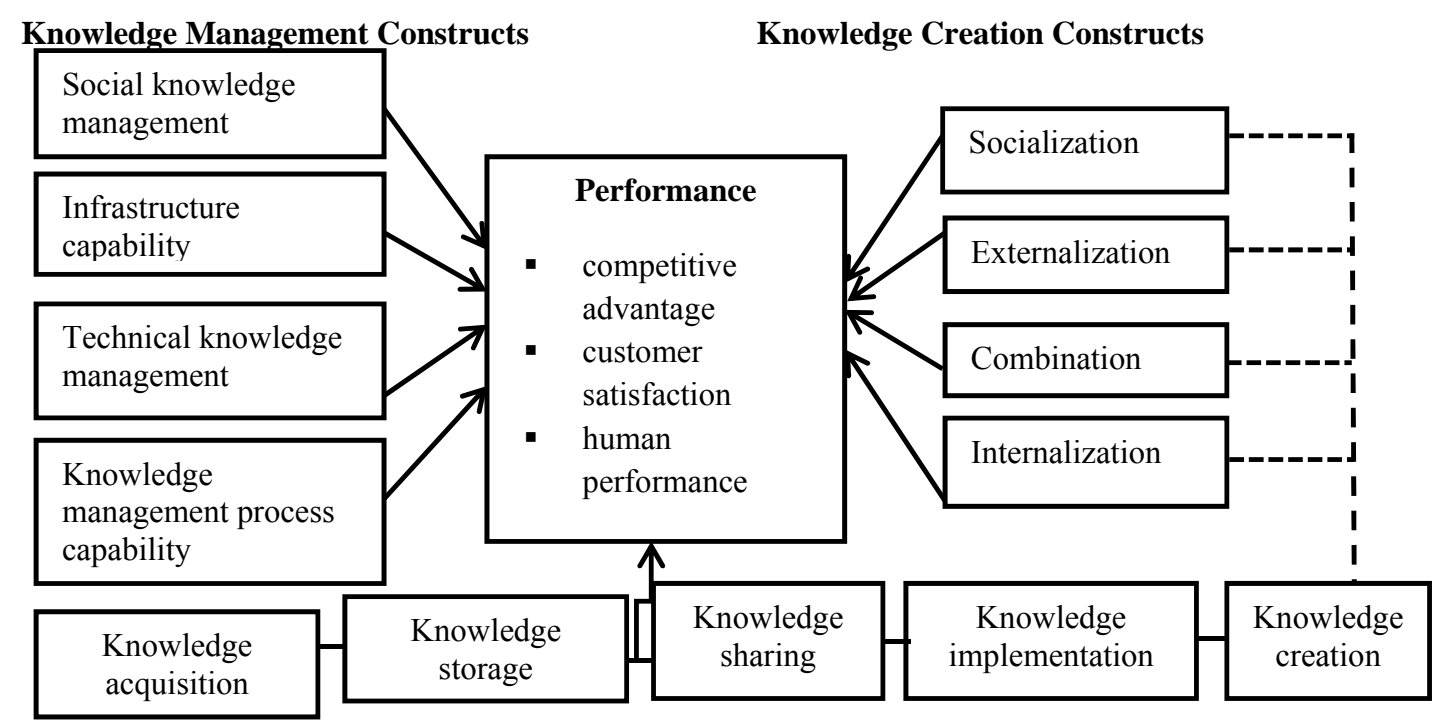

Fig. 1. Conceptual framework

Source: Nonaka and Takeuchi (1995), McKeen and Singh (2009), Nguyen (2010), Bihamta et al. (2012), Na and Kang (2018), Abusweilem and Abualoush (2019)

Nguyen (2010) expressed that the multi-dimensional constructs of Knowledge Management (social knowledge management, infrastructure capability, technical knowledge management, and knowledge management process capability contribute to the firm's competitiveness. Knowledge Management was defined by Gloet and Terziovski (2004) as the admission and formalization of knowledge, experience, and skills that build new capacity, promote improved performance and encourage creativity along with increased customer value. Previous researches have also explained Knowledge Management under the expression of an umbrella on behalf of a range of interlinking expressions. Previous studies have been able to clarify Knowledge Management on several interlinked terms. For example, Hussain, Qurashi, Mujtaba, Waseem, \& Iqbal (2019) identified the terms as "creation of knowledge, valuation, and metrics of knowledge, mapping, and indexing of knowledge, transport of knowledge, storage, distribution and sharing of knowledge" (p.3). 


\section{Methodology}

\section{Research Design}

The research survey design was adopted, and it was focused on the SME sector. Adopting this approach enhances the authenticity of the study. The study was designed to use only primary survey-based data.

\section{The population of the study}

SMEs were objects of interest. These were SMEs that have operated in Kogi State and also registered with Small and Medium Enterprises Development Agency of Nigeria. The populations are 827 small enterprises and 17 medium enterprises, making 844 in totality. The variables for segmenting the SMEs were total assets and employment brand. The small enterprises possess 10 to 49 employees and medium enterprises have 50-199 employees (Small and Medium Development Agency of Nigeria and the National Bureau of Statistics, 2017). The activity fields of the SMEs include 'transport/storage, manufacturing, and wholesaling/retailing trade. The population was sparsed across the three Senatorial Districts of Kogi State (Kogi East, West, and Central).

\section{Sample size and sampling technique}

In this study, the multistage random sampling technique was adopted. This is because the study identified two-in-one aggregate study groups that form different clusters. 827 Small Enterprises were randomly selected. So also, 17 Medium Enterprises were selected with a non-random sampling technique. In choosing the sampling size and securing representative responses, the size of the sample was based on non-statistical estimation. Thus, a purposive sample was used. Pseudosampling was employed for the purposive sample. The selection criteria for the SMEs were business registration, legitimate product/services, and business experience (at least five years).

\section{Validity and reliability}

The study used two methods for validity. Theoretical validity and content validity were used. Theoretical validity was achieved through extensive literature review, and content validity was achieved through the editing and reconstruction of measuring variables by academics and professionals.

Reliability was therefore confirmed using Cronbach's Alpha. The results indicated a high level of internal consistency for constructs: socialization (0.87), externalization (0.70), combination (0.87), internalization (0.71), knowledge acquisition (0.73), knowledge storage (0.75), knowledge creation (0.89), knowledge sharing (0.79), knowledge implementation (0.78), competitive advantage $(0.80)$ and business survival $(0.70)$.

\section{Questionnaire structure}

Data were collected using a well-structured questionnaire. The questionnaire was close-ended. A five-point Likert Scale was used to measure the salient variables:

\begin{tabular}{lc}
\multicolumn{1}{c}{ Scale } & Point \\
Strongly Agree & 5 \\
Agree & 4 \\
Neutral & 3 \\
Disagree & 2 \\
Strongly Disagree & 1
\end{tabular}


The Likert Scale is a widely accepted method for data collection. The scaling of the questionnaire ensured that needed information was elicited and quick understanding was facilitated. The degree of responses was enhanced using the 1-5 scale.

\section{Method of data analysis}

The data generated for the study were analyzed using both descriptive and inferential analytical techniques. The analytical technique employed was multiple regression models. The study used stepwise multiple regressions for objective one; where the $\mathrm{R}^{2}$ of individual variables were determined in a single table. Knowledge creation was proxied with combination, internalization, socialization, and externalization. The models are specified below:

$$
\mathbf{C M A}=\mathbf{a}+\beta_{1} \mathbf{C B N}+\beta_{2} \mathbf{I N N}+\beta_{3} \mathbf{S Z N}+\beta_{4} \mathbf{E T N}+\mathrm{e}
$$

Where:

$\mathrm{CMA}=$ Dependent variable (Competitive Advantage);

$\mathrm{a}=$ constant;

CBN, INN, SZN \& ETN reflect the independent variables (combination, internalization, socialization, and externalization);

$\mathbf{C B N}=$ Combination;

INN = Internalization;

SZN = Socialization;

ETN = Externalization;

$\beta_{1}, \beta_{2}, \beta_{3}, \beta_{4}=$ regression coefficients;

$\mathbf{e}=$ Stochastic error term.

The stepwise multiple regressions were also used for objective two. Knowledge management was proxied with knowledge transfer, knowledge storage, motivation, knowledge acquisition and knowledge use. The model is specified below:

$$
\mathrm{BNS}=\mathrm{a}+\beta_{1} \mathbf{K L T}+\beta_{2} \mathbf{K L S}+\beta_{3} \mathbf{M T N}+\beta_{4} \mathbf{K L A}+\beta_{5} \mathbf{K L U}+\mathrm{e}
$$

Where:

BNS $=$ Dependent variable (Business Survival);

$\mathrm{a}=$ constant;

KLT, KLS, MTN, KLA, \& KLU reflect the independent variables (knowledge transfer, knowledge storage, motivation, knowledge acquisition and knowledge use);

KLT $=$ Knowledge transfer;

KLS = Knowledge storage;

MTN = Motivation;

KLA = Knowledge acquisition;

KLU = Knowledge use;

$\beta_{1}, \beta_{2}, \beta_{3}, \beta_{4}=$ regression coefficients;

$\mathbf{e}=$ Stochastic error term. 


\section{Analysis and Results}

Table 1. Showing descriptive statistics of knowledge creation

\begin{tabular}{|l|c|c|}
\hline Knowledge Creation & Mean & Std. Deviation \\
\hline Socialization (social interaction) & 2.4124 & 1.33855 \\
\hline $\begin{array}{l}\text { Externalization (copying the knowledge created by other } \\
\text { competitors) }\end{array}$ & 2.0916 & 1.14932 \\
\hline Combination (organizing and integrating knowledge ) & 2.2430 & 1.22544 \\
\hline $\begin{array}{l}\text { Internalization (knowledge receiving and application by } \\
\text { an individual in the enterprise) }\end{array}$ & 2.4582 & 1.29995 \\
\hline
\end{tabular}

Source: Field Survey (2020).

Table 1 describes the statistical strength of socialization $($ mean $=2.4124$; standard deviation $=$ $1.33855)$, externalization $($ mean $=2.0916$; standard deviation $=1.14932)$, combination $($ mean $=$ 2.2430; standard deviation $=1.22544)$ and internalization $($ mean $=2.4582 ;$ standard deviation $=$ 1.29995). Internalization has the highest mean score with a very high deviation. This shows that the data-set clusters more around the mean. There is also an indication of more variation in internalization of knowledge. The other variables' standard deviation also shows more divergence from the mean. Meanwhile, all the variables have strong mean scores. The variables measure knowledge creation very well.

Table 2. Showing descriptive statistics of knowledge management credence

\begin{tabular}{|l|c|c|}
\hline KM & Mean & Std. Deviation \\
\hline The use of knowledge & 2.4712 & 1.28996 \\
\hline Knowledge acquisition at individual level & 2.2903 & 1.20723 \\
\hline Knowledge storage & 2.0457 & 1.22714 \\
\hline Motivation & 2.3757 & 1.20753 \\
\hline Knowledge transfer & 1.9205 & 1.12807 \\
\hline
\end{tabular}

Source: Field Survey (2020).

Table 2 shows the mean score of use of knowledge (mean $=2.4712$; standard deviation $=$ 1.28996), knowledge acquisition at individual level (mean $=2.2903$; standard deviation $=$ $1.20723)$, knowledge storage $($ mean $=2.0457$; standard deviation $=1.22714)$, motivation $($ mean $=2.3757$; standard deviation $=1.20753)$ and knowledge transfer (mean $=1.9205$; standard deviation $=1.12807)$. The standard deviation of the variables indicates more cluster around the mean. However, the variables' mean score signify that the variables measure the knowledge management practice of SMEs. The 'use of knowledge' has the high mean, but there is a lot of variation in how knowledge is used. Knowledge transfer has the least mean with the least variation with respect to the value (1.12807); implying that there is much less variation in knowledge transfer.

Table 3. Showing descriptive statistics of SMEs' Performance

\begin{tabular}{|l|c|c|c|c|}
\hline \multirow{2}{*}{} & Mean & Std. Deviation & \multicolumn{2}{|c|}{ Skewness } \\
\cline { 2 - 5 } & Statistic & Statistic & Statistic & Std. Error \\
\hline Competitive advantage & 1.4315 & .49632 & .278 & .157 \\
\hline Business survival & 2.2116 & 1.38475 & .792 & .157 \\
\hline
\end{tabular}

Source: Field Survey (2020).

Table 3 shows the mean score of competitive advantage $($ mean $=1.4315$; standard deviation $=$ 0.49632 ) and business survival (mean $=2.2116$; standard deviation $=1.38475$ ). Competitive advantage has lesser mean with lesser variation in value. This implies little divergence from the average value. Business survival shows stronger mean value with more variation in value. This is an indication of high variations in the business survival of SMEs. The skewness of competitive advantage shows a value (0.278) less than \pm 1.0 ; indicating that the result is still 
within normality in the distribution. The skewness of business survival shows a value $(0.792)$ which is also less than \pm 1.0 ; the distribution is considered normal.

Table 4. Model Summary of knowledge creation constructs and competitive advantage

\begin{tabular}{|l|c|c|c|c|}
\hline $\begin{array}{l}\text { Model } \\
\text { (code) }\end{array}$ & R & R Square & Adjusted R Square & $\begin{array}{c}\text { Std. Error of the } \\
\text { Estimate }\end{array}$ \\
\hline CBN & $.778^{\mathrm{a}}$ & .605 & .604 & .80859 \\
\hline INN & $.846^{\mathrm{b}}$ & .716 & .715 & .68614 \\
\hline SZN & $.871^{\mathrm{c}}$ & .758 & .756 & .63425 \\
\hline ETN & $.890^{\mathrm{d}}$ & .793 & .791 & .58727 \\
\hline
\end{tabular}

Predictors in the Model: combination, internalization, socialization, and externalization.

Dependent Variable: Competitive advantage.

Source: Field Survey (2020).

Table 4 shows the effects of four variables (such as combination, internalization, socialization, and externalization) on the competitive advantage of SMEs in Kogi State. The adjusted Rsquared compares the goodness-of-fit for the regression models that contain differing numbers of the independent variables (combination- 0.604, internalization - 0.715, socialization- 0.756 and externalization- 0.791). The result of the coefficient of determinations shows that combination $\left(\mathrm{R}^{2}=0.605\right)$, internalization $\left(\mathrm{R}^{2}=0.716\right)$, socialization $\left(\mathrm{R}^{2}=0.758\right)$ and externalization $\left(\mathrm{R}^{2}=0.793\right)$ have explanatory power over competitive advantage. It is seen that a $60.5 \%$ variation in competitive advantage is explained by the combination of resources. $71.6 \%$ variation in competitive advantage is explained by internalization; $75.8 \%$ variation in competitive advantage is explained by socialization, and $79.3 \%$ variation in competitive advantage is explained by externalization. The unexplained variations (combination $-39.5 \%$, internalization $-28.4 \%$, socialization $-24.2 \%$, and externalization $-20.7 \%$ ) show that other variables can predict the competitive advantage of SMEs in Kogi State. All the coefficient of determinations $\left(\mathrm{R}^{2}\right.$ value) proved that these variables have strong effects on competitive advantage.

Table 5. Coefficients of knowledge creation and competitive advantage of SMEs

\begin{tabular}{|c|c|c|c|c|c|c|}
\hline & \multirow{2}{*}{ Model } & \multicolumn{2}{|c|}{$\begin{array}{c}\text { Unstandardized } \\
\text { Coefficients }\end{array}$} & \multirow{2}{*}{$\begin{array}{c}\text { Standardized } \\
\text { Coefficients } \\
\text { Beta } \\
\end{array}$} & \multirow{2}{*}{$\mathbf{T}$} & \multirow{2}{*}{ Sig. } \\
\hline & & B & $\begin{array}{c}\text { Std. } \\
\text { Error }\end{array}$ & & & \\
\hline \multirow{2}{*}{1} & (Constant) & .691 & .075 & & 9.168 & .000 \\
\hline & Combination & .816 & .029 & .778 & 27.665 & .000 \\
\hline \multirow{3}{*}{2} & (Constant) & .301 & .070 & & 4.323 & .000 \\
\hline & Combination & .508 & .033 & .484 & 15.248 & .000 \\
\hline & Internalization & .439 & .031 & .444 & 13.978 & .000 \\
\hline \multirow{4}{*}{3} & (Constant) & .609 & .072 & & 8.399 & .000 \\
\hline & Combination & .538 & .031 & .513 & 17.378 & .000 \\
\hline & Internalization & .495 & .030 & .501 & 16.690 & .000 \\
\hline & Externalization & -.245 & .026 & -.219 & -9.273 & .000 \\
\hline \multirow{5}{*}{4} & (Constant) & .459 & .069 & & 6.641 & .000 \\
\hline & Combination & .390 & .033 & .372 & 11.849 & .000 \\
\hline & Internalization & .439 & .028 & .444 & 15.613 & .000 \\
\hline & Externalization & -.237 & .024 & -.212 & -9.691 & .000 \\
\hline & Socialization & .250 & .027 & .260 & 9.157 & .000 \\
\hline
\end{tabular}

Dependent Variable: Competitive advantage.

Source: Field Survey (2020).

Table 5 shows the coefficients of the variables and competitive advantage. The coefficient of combination (unstandardized beta - 0.816) shows a positive relationship with a competitive 
advantage. The coefficient of combination (standardized beta -0.778 ; $p$-value $=0.01$ ) shows greater contribution to competitive advantage. The unstandardized beta $(0.508)$ for combination is high compared with the unstandardized beta (0.439) for internalization. It is seen also that combination has more contribution to a competitive advantage when compared with internalization. This is sequel to the results that combination (standardized beta - 0.484) and internalization (standardized beta -0.444 ) are significant (given $p$-value $=0.01$ ). The result proves that internalization has a positive relationship with a competitive advantage.

The results in Table 5 also show that combination has the highest coefficient (unstandardized beta - 0.538) compared with internalization (unstandardized beta - 0.495) and externalization (unstandardized beta - -0.245). Combination has the highest contribution to the competitive advantage; given combination (standardized beta -0.513 ; $\mathrm{p}$-value $=0.01$ ), internalization (standardized beta $-0.501 ; \mathrm{p}$-value $=0.01$ ) and externalization (standardized beta $--0.219 ; \mathrm{p}$ value $=0.01)$. The result proves that externalization has negative relationship with competitive advantage.

Finally, the results in Table 5 show that the inclusion of socialization made internalization to have the highest coefficient (unstandardized beta - 0.439) compared with combination (unstandardized beta - 0.390), socialization (unstandardized beta - 0.250) and externalization (unstandardized beta - -0.237). Internalization also has the highest contribution to competitive advantage; given internalization (standardized beta -0.444 ; $\mathrm{p}$-value $=0.01$ ), combination (standardized beta $-0.372 ;$ p-value $=0.01$ ), socialization (standardized beta -0.260 ) and externalization (standardized beta --0.212 ; $\mathrm{p}$-value $=0.01$ ). The result proves that socialization has positive relationship with competitive advantage.

Table 6. Model Summary of knowledge management activities and business survival

\begin{tabular}{|l|c|c|c|c|}
\hline \multicolumn{1}{|c|}{ Model } & $\mathbf{R}$ & R Square & Adjusted R Square & $\begin{array}{c}\text { Std. Error of the } \\
\text { Estimate }\end{array}$ \\
\hline KLT & $.873^{\mathrm{a}}$ & .762 & .762 & .63659 \\
\hline KLS & $.908^{\mathrm{b}}$ & .824 & .823 & .54809 \\
\hline MTN & $.922^{\mathrm{c}}$ & .850 & .849 & .50715 \\
\hline KLA & $.929^{\mathrm{d}}$ & .863 & .861 & .48532 \\
\hline KLU & $.930^{\mathrm{e}}$ & .865 & .863 & .48193 \\
\hline
\end{tabular}

Predictors: knowledge transfer, knowledge storage, motivation, knowledge acquisition and knowledge use.

Dependent Variable: Business survival.

Source: Field Survey (2020).

Table 6 shows the effects of five variables (knowledge transfer, knowledge storage, motivation, knowledge acquisition, and knowledge use) on the business survival of SMEs in Kogi State. The adjusted R-squared compares the goodness-of-fit for the regression models that contain different numbers of the independent variables (knowledge transfer - 0.762, knowledge storage 0.823 , motivation -0.849 , knowledge acquisition - 0.861nd knowledge use - 0.863). The result of the coefficient of determinations shows that knowledge transfer $\left(\mathrm{R}^{2}=0.762\right)$, knowledge storage $\left(\mathrm{R}^{2}=0.824\right)$, motivation $\left(\mathrm{R}^{2}=0.850\right)$, knowledge acquisition $\left(\mathrm{R}^{2}=0.863\right)$, and knowledge use $\left(\mathrm{R}^{2}=0.865\right)$ have explanatory power over business survival. It is seen that $76.2 \%$ variation in business survival is explained by knowledge transfer; $82.4 \%$ variation in business survival is explained by knowledge storage; $85.0 \%$ variation in business survival is explained by motivation; 86.3 variations in business survival are explained by knowledge acquisition and $86.5 \%$ variation in business survival is explained by knowledge use. The unexplained variations (knowledge transfer- $23.8 \%$, knowledge storage $-17.6 \%$, motivation$15.0 \%$, knowledge acquisition - 13.7 and knowledge use $-13.5 \%$ ) show that other variables can predict the business survival of SMEs in Kogi State. All the coefficient of determinations $\left(\mathrm{R}^{2}\right.$ value) proved that these variables have strong effects on business survival. 
Table 7.: Coefficients of knowledge management activities and business survival of SMEs

\begin{tabular}{|c|c|c|c|c|c|c|}
\hline & \multirow{2}{*}{ Model } & \multicolumn{2}{|c|}{$\begin{array}{c}\text { Unstandardized } \\
\text { Coefficients }\end{array}$} & \multirow{2}{*}{$\begin{array}{c}\text { Standardized } \\
\text { Coefficients } \\
\text { Beta }\end{array}$} & \multirow{2}{*}{$\mathbf{T}$} & \multirow{2}{*}{ Sig. } \\
\hline & & B & $\begin{array}{c}\text { Std. } \\
\text { Error }\end{array}$ & & & \\
\hline \multirow{2}{*}{1} & (Constant) & .267 & .056 & & 4.746 & .000 \\
\hline & Knowledge transfer & 1.016 & .025 & .873 & 40.018 & .000 \\
\hline \multirow{3}{*}{2} & (Constant) & .125 & .050 & & 2.517 & .012 \\
\hline & Knowledge transfer & .578 & .040 & .497 & 14.595 & .000 \\
\hline & Knowledge storage & .480 & .036 & .451 & 13.248 & .000 \\
\hline \multirow{4}{*}{3} & (Constant) & -.062 & .050 & & -1.226 & .221 \\
\hline & Knowledge transfer & .407 & .041 & .350 & 9.916 & .000 \\
\hline & Knowledge storage & .344 & .037 & .323 & 9.388 & .000 \\
\hline & Motivation & .334 & .036 & .308 & 9.210 & .000 \\
\hline \multirow{5}{*}{4} & (Constant) & .091 & .053 & & 1.716 & .087 \\
\hline & Knowledge transfer & .424 & .039 & .364 & 10.763 & .000 \\
\hline & Knowledge storage & .324 & .035 & .305 & 9.223 & .000 \\
\hline & Motivation & .412 & .037 & .380 & 11.282 & .000 \\
\hline & $\begin{array}{l}\text { Knowledge } \\
\text { acquisition }\end{array}$ & -.144 & .021 & -.133 & -6.841 & .000 \\
\hline \multirow{6}{*}{5} & (Constant) & .127 & .054 & & 2.354 & .019 \\
\hline & Knowledge transfer & .411 & .039 & .353 & 10.451 & .000 \\
\hline & Knowledge storage & .326 & .035 & .307 & 9.345 & .000 \\
\hline & Motivation & .453 & .039 & .418 & 11.600 & .000 \\
\hline & $\begin{array}{l}\text { Knowledge } \\
\text { acquisition }\end{array}$ & -.124 & .022 & -.115 & -5.631 & .000 \\
\hline & Knowledge use & -.065 & .023 & -.064 & -2.833 & .005 \\
\hline
\end{tabular}

Dependent Variable: Business survival.

Source: Field Survey (2020)

Table 7 shows the coefficients of the variables and business survival. Keeping all other variables constant, the coefficient of knowledge transfer (unstandardized beta - 1.016) shows a positive relationship with business survival. The result shows that over $100 \%$ relationship exists between knowledge transfer and business survival. This may imply that the more knowledge is transferred the more the tendency of SMEs' survival in the business environment. The coefficient of knowledge transfer (standardized beta -0.873 ; p-value $=0.01$ ) shows greater contribution to business survival. The implication of this is that when knowledge is transferred within the SME sector, SMEs are likely to survive any threat in the business environment.

The result shows the unstandardized beta $(0.578)$ for knowledge transfer and the unstandardized beta $(0.480)$ for knowledge storage. The coefficients are below $50 \%$. It is seen also that knowledge transfer has more contribution to business survival compared to knowledge storage; given the values of knowledge transfer (standardized beta -0.497 ; p-value $=0.01$ ) and knowledge storage (standardized beta -0.451 ; p-value $=0.01$ ). Knowledge storage has kept knowledge transfer to remain high in the model. The result also proves that knowledge storage has a positive contribution to the business survival of SMEs in Kogi State.

The result in Table 7 shows that knowledge transfer still has the highest coefficient despite the inclusion of motivation. Knowledge transfer has the highest coefficient (unstandardized beta 0.407) when compared with knowledge storage (unstandardized beta - 0.344) and motivation (unstandardized beta - 0.334). Knowledge transfer has the highest contribution to business survival; given Knowledge transfer (standardized beta -0.350 ; p-value $=0.01$ ), knowledge storage (standardized beta $-0.323 ; \mathrm{p}$-value $=0.01$ ) and motivation (standardized beta $-0.308 ; \mathrm{p}$ value $=0.01$ ). The result proves that motivation has a positive contribution to the business survival of SMEs in Kogi State. 
Furthermore, Table 7 also shows that the inclusion of knowledge acquisition to the model made the value of motivation to increase and knowledge transfer to remain the highest. Knowledge transfer has the highest coefficient (unstandardized beta - 0.424) compared to motivation (unstandardized beta - 0.412), knowledge storage (unstandardized beta - 0.324) and Knowledge acquisition (unstandardized beta - -0.144). Meanwhile, motivation has the highest contribution to business survival; given that motivation (standardized beta $-0.380 ; \mathrm{p}$-value $=0.01$ ), knowledge transfer (standardized beta - 0.364; p-value $=0.01$ ), knowledge storage (standardized beta $-0.305 ; \mathrm{p}$-value $=0.01$ ) and knowledge acquisition (standardized beta - 0.133 ; $\mathrm{p}$-value $=0.01$ ). The relationship between knowledge transfer and business survival of SMEs in Kogi State appears to be high and positive, but motivation seems to have more contribution to the business survival of SMEs than knowledge transfer. The result proves that the contribution of knowledge acquisition to the business survival of SMEs is negative.

Finally, the Table 7 shows that motivation has the highest coefficient (unstandardized beta 0.453) compared to knowledge transfer (unstandardized beta - 0.411), knowledge storage (unstandardized beta - 0.326), knowledge acquisition (unstandardized beta - -0.124) and knowledge use (unstandardized beta - -0.065). Motivation also has the highest contribution to business survival; given that motivation (standardized beta -0.418 ; $p$-value $=0.01$ ), knowledge transfer (standardized beta $-0.353 ; \mathrm{p}$-value $=0.01$ ), knowledge storage (standardized beta 0.307 ; $\mathrm{p}$-value $=0.01)$, knowledge acquisition ( standardized beta $-0.115 ; \mathrm{p}$-value $=0.01$ ) and knowledge use (standardized beta --0.064 ; $p$-value $=0.01$ ). The result proves that knowledge acquisition and knowledge use has negative contributions to the business survival of SMEs in Kogi State.

\section{Discussion of Findings}

Findings show that knowledge creation constructs (combination, internalization, socialization, and externalization) have strong predictive power over the competitive advantage of SMEs in Kogi State. Among the variables, externalization appears to be the strongest. The result shows that a combination in knowledge creation has a positive relationship with a competitive advantage. On individual assessment, it has a greater contribution to competitive advantage. The contribution of combination to the competitive advantage of SMEs is positive. Internalization has a positive relationship with a competitive advantage. Also, its contribution to competitive advantage is found positive. It was also found that externalization has a negative relationship with a competitive advantage. The contribution of externalization to competitive advantage was also found to be positive. More so, finding shows that socialization has a positive relationship with a competitive advantage. It was equally found that socialization contributes positively to the competitive advantage of SMEs in Kogi State. This finding supports the assertion of Organizational Knowledge Creation Theory by Nonaka and Takeuchi (1995) that socialization can influence the competitive advantage of a firm.

Findings show that knowledge transfer, knowledge storage, motivation, knowledge acquisition, and knowledge use have strong predicting power over the business survival of SMEs in Kogi State. The results proved that knowledge storage, motivation, knowledge acquisition, and knowledge use have very strong predicting power. Finding further shows that knowledge transfer has a positive relationship with business survival. The more knowledge is transferred the more the tendency of SMEs' survival in the business environment. Knowledge transfer has a greater contribution to the business survival of SMEs in Kogi State. The transfer of knowledge within the SME sector is likely to cause, SMEs' survival in the business environment. It was found that the relationship between knowledge storage and business survival of SMEs is positive but weak. Knowledge transfer has more contribution to business survival compared to knowledge storage. Even if knowledge storage is combined with knowledge transfer in the model, knowledge transfer will continue to increase. It was found that knowledge storage has a positive contribution to the business survival of SMEs in Kogi State. It was found that 
knowledge transfer has the highest coefficient value despite the inclusion of motivation. Knowledge transfer has the highest contribution to business survival. Meanwhile, motivation has a positive contribution to the business survival of SMEs in Kogi State. Finding further shows that the inclusion of knowledge acquisition to the model increases the value of motivation and knowledge transfer. Knowledge transfer was found to have the highest relationship with the business survival of SMEs, but motivation has the highest contribution to the business survival of SMEs is negative. Knowledge acquisition and knowledge use have negative contributions to the business survival of SMEs in Kogi State.

\section{Conclusions}

Knowledge is created through the interaction of tacit and explicit knowledge. The theoretical underpinning of this study provides that socialization, internationalization, externalization and combination interpret the knowledge transit or knowledge creation (through the interaction of tacit and explicit knowledge). These have possible consequences on the performance of SMEs in Kogi State. Also, the ability of SME owners to manage knowledge can translate into better chance of achieving the enterprise's goals. Previously, there have been empirical confirmations that knowledge management activities have effect on the performance of firms.

This study provides empirical evidence that socialization have the tendency to enhance or facilitate the achievement of the competitive advantage of both Small and Medium Enterprises in Kogi State. Knowledge created through socialization is likely to bring about sustainability of competitive advantage. When there is high level of social interaction by SME owners (particularly in a strong social network) the chance to achieve and sustain competitive position also stands. Medium Enterprises have gained or created knowledge through externalization in Kogi State. This has significantly led to the achievement of their competitive advantage in the business environment of Kogi State. It is evident based on the empirical prove that knowledge created through externalization has insignificant effect on the competitive advantage of Small Enterprises in Kogi State. Knowledge created through combination of resources has significant effect on the competitive advantage of both Small and Medium Enterprises in Kogi State. There is no significant relationship between internalization and the competitive advantage of SMEs in Kogi State. All these support and validate the SECI model. Thus, the assumption of Organizational Knowledge Creation Theory that socialization, internationalization, externalization and combination have predictive power over the competitive advantage of firms stands the test of time. The assumption also holds in the case of SMEs in Kogi State.

\section{Recommendations}

The study has presented some findings in response to its objectives. Based on the findings, the following recommendations are made that:

o SME owners should channel their knowledge creation towards socialization. Owners of Medium Enterprises should take advantage of knowledge creation through externalization to facilitate sustainable competitive advantage in Kogi State. Knowledge creation through externalization should be discouraged by Small Enterprise owners in Kogi State. Both Small and Medium Enterprises should take advantage of knowledge creation through combination of resources. Owners of SMEs should give less attention to knowledge creation through internalization. The practicability of all these will increase their chance of sustaining their competitive advantage in Kogi State.

o SME owners and economic stakeholders should find alternative ways of promoting effective knowledge management and creation in Kogi State. The survival of SMEs is dependent on the effectiveness of knowledge management and creation activities. Since SMEs are cardinal to the economy of Kogi State, thus the government should establish an 
intervention programme to support their knowledge management and creation activities. Once this is practically put in place, more SMEs will survive the turbulent business environment of Kogi State.

\section{References}

1. Abusweilem, M.A. \& Abualoush, S. (2019). The impact of knowledge management process and business intelligence on organizational performance. Management Science Letters. 9, 2143-2156. doi: $10.5267 /$ j.msl.2019.6.020.

2. Ahlstrom, D. (2010). Innovation and growth: how business contributes to society. Academy of Management Perspectives, 24(1): 10-23.

3. Bihamta, H., Nowzari, D., Eghtebasi, S., Subramaniam, I.D., Salimi, M. and Salehi, M. (2012). A Descriptive Study on the Impact of Knowledge Creation Mechanism on Organizational Performance: A Case study in Malaysian Automotive industry. International Journal of Academic Research in Business and Social Sciences. 2(7), 256-265.

4. Chen, D.N. and Liang, T.P. (2011). Knowledge Evolution Strategies and Organizational Performance: A Strategic Fit Analysis. Electronic Commerce Research and Applications, 10(1), 7584.

5. Duggan, W. (2012). Creative Strategy: A Guide for Innovation. New York: Columbia University Press.

6. Easterby-Smith, M., \& Lyles, M. A. (2011). Handbook of organizational learning and knowledge management. Chichester: John Wiley \& Sons.

7. Fugate, B.S., Stank, T.P. and Mentzer, J.T. (2009). Linking Improved Knowledge Management to Operational and Organizational Performance. Journal of Operations Management, 27(3), 247-264.

8. Gloet, M. and Terziovski, M. (2004). Exploring the relationship between knowledge management practices and innovation performance. Journal of Manufacturing Technology Management, 15(5), 402-409.

9. Gonzalez, A.M. (2010). The U.S. Army: A Learning Organization. SSRN eLibrary.

10. Handzic, M. and Hasan, H. (2003), 'Continuing the Knowledge Management Journey', chapter 16. In H. Hasan and M. Handzic (eds). Australian Studies in Knowledge Management, UOW Press, Wollongong, pp 520-554.

11. Huang, T.C. (2001) The Relation of Training Practices and Organizational Performance in Small and Medium Size Enterprises. Education+ Training, 43(8/9), 437-444.

12. Hussain, I., Xiaoyu, Y.U., Si, L.W.S. and Ahmed, S. (2011). Organizational Knowledge Management Capabilities and Knowledge Management Success (KMS) in Small and Medium Enterprises (SMEs). African Journal of Business Management, 5(22), 8971-8979.

13. Hussain, I., Qurashi, A., Mujtaba, G., Waseem, M. A., \& Iqbal, Z. (2019). Knowledge management: a roadmap for innovation in SMEs' sector of Azad Jammu \& Kashmir. Journal of Global Entrepreneurship Research, 9(1). doi:10.1186/s40497-018-0120-8.

14. Kamya, M.T., Ntayi, J.M. and Ahiauzu, A. (2010). Knowledge management and competitive advantage: The interaction effect of market orientation. African Journal of Business Management. 4(14), 2971-2980.

15. Kiessling, T.S., Richey, R.G., Meng, J. and Dabic, M. (2009). Exploring Knowledge Management to Organizational Performance Outcomes in a Transitional Economy. Journal of World Business, 44(4), 421-433.

16. Knowledge Management in ADB (2004). Asian Development Bank. Retrieved 14/10/2018, from http://adb.org/sites/default/files/pub/2004/knowledge-management.pdf

17. Lewin, A. andMassini, S.(2004). Knowledge Creation and Organizational Capabilities of Innovating and Imitating Firms.In: C. Riera and J. Iijima (eds.). Linking Knowledge Creating Capabilities, IT Business Value and Digital Business Value: An Exploratory Study in Japanese SMEs. Proceedings of the 9th International Joint Conference on Knowledge Discovery, Knowledge Engineering and Knowledge Management (KMIS 2017), pages 29-40. DOI: 10.5220/0006487900290040.

18. Na, Y.K. and Kang, S. (2018). Effects of Core Resource and Competence Characteristics of Sharing Economy Business on Shared Value, Distinctive Competitive Advantage, and Behavior Intention. Sustainability, 10(1), 1-17. doi:10.3390/su10103416.

19. Nawab, S., Nazir, T., Zahid, M.M. and Fawad, S.M. (2015). Knowledge Management, Innovation and Organizational Performance. International Journal of Knowledge Engineering, 1(1): 43-48 
20. Nguyen, T.N.Q. (2010). Knowledge management capability and competitive advantage: an empirical study of Vietnamese enterprises, PhD thesis, Southern Cross University, Lismore, NSW

21. Nonaka, I. (2017). The Knowledge-Creating Company: Managing for the Long Term. Harvard Business Review. Retrieved on 21/09/2019 from hbr.orgl.

22. Nonaka, I. and Von Krogh, G. (2009). Tacit knowledge and knowledge conversion: Controversy and advancement in organizational knowledge creation theory. Organization Science, 20(3): 635-652

23. Nonaka, I., Kodama, M., Hirose, A. and Kohlbacher, F. (2014). Dynamic fractal organizations for promoting knowledge-based transformation-A new paradigm for organizational theory. Eur.Manag. J. 32(1): 137-146. Retrieved on 21/07/2019 from https://doi.org/10.1016/j.emj.2013.02.003.

24. Nonaka, I., Toyama, R. and Konno, N. (2015). SECI, Ba, and leadership: a unified model of dynamic knowledge creation. Long Range Planning, 33, pp 5-34.

25. O'Regan, N. and Ghobadian, A. (2004). The importance of capabilities for strategic direction and performance, Management Decision, 42(2), 292- 312.

26. Riera, C. and Iijima, J. (2017). Linking Knowledge Creating Capabilities, IT Business Value and Digital Business Value: An Exploratory Study in Japanese SMEs. Proceedings of the 9th International Joint Conference on Knowledge Discovery, Knowledge Engineering and Knowledge Management (KMIS 2017), pages 29-40. DOI: 10.5220/0006487900290040.

27. Salojärvi, S., Furu, P. and Sveiby, E.K. (2005). Knowledge management and growth in finnish SMEs, Journal of Knowledge Management, 9(1): 103-122.

28. Small and Medium Development Agency of Nigeria (SMEDAN) and the National Bureau of Statistics (NBS) (2017). National Survey of Micro Small and Medium Enterprises. Retrieved from http://smedan.gov.ng/images/NATIONAL\%20SURVEY\%20OF\%20MICRO\%20SMALL\%20\&\%2 0MEDIUM\%20ENTERPRISES\%20(MSMES),\%20\%202017\%201.pdf.

29. Sofka, W. and Grimpe, C. (2010) 'specialized search and innovation performance: evidence across Europe'. R\&D Management, 40(1), 310-323.

30. Szulanski, G. (2001). Knowledge creation: A source of value. Academy of Management Review, 26(2), 318-320.

31. Teece, D., Pisano, G. and Shuen, A. (1997). Dynamic capabilities and strategic management, Strategic Management Journal, 18, 509-533.

32. Von Krogh, G., Ichijo, K. and Nonaka, I. (2015), Enabling Knowledge Creation, New York: Oxford University Press Inc.

33. Wang, D., Su, Z., \& Yang, D. (2011).Organizational culture and knowledge creation capability. Journal of Knowledge Management, 15(3), 363-373.

34. Wang, H., \& Wu, C. (2011). Green growth as the best choice for Chinese small and medium enterprises in sustainable development. Asian Social Science, 7(5), 81-95 Retrieved on 23/07/2019 from http://dx.doi.org/10.5539/ass.v7n5p81.

35. Zack, M., McKeen, J., and Singh, S. (2009). Knowledge Management and Organizational Performance: an Exploratory Analysis. Journal of Knowledge Management, 13(6), 392-409. 